\title{
Optimization Study of Outburst Prevention Measures for Tuzhu Coal Mine Based on Fixed Weight Clustering Analysis
}

\author{
Wenke Luo ${ }^{1,2}$, Shiliang Shi1,2, Yi Lu ${ }^{1,2 *}$, Shenghua Zou1,2, Zaian Chen ${ }^{3}$, Liliang Chen ${ }^{4}$ \\ ${ }^{1}$ Hunan Provincial Key Laboratory of Safe Mining Techniques of Coal Mines, Xiangtan, China \\ ${ }^{2}$ School of Energy and Safety Engineering, Hunan University of Science and Technology, Xiangtan, China \\ ${ }^{3}$ Jinzhushan Mining Company of Hunan Coal Group, Lenshuijiang, China \\ ${ }^{4}$ Baishanping Mining of Hunan Black Gold Era Co., LTD, Leiyang, China \\ Email: "luyijx@163.com
}

Received 21 December 2015; accepted 26 January 2016; published 29 January 2016

Copyright (C) 2016 by author(s) and Scientific Research Publishing Inc.

This work is licensed under the Creative Commons Attribution International License (CC BY). http://creativecommons.org/licenses/by/4.0/

(c) (i) Open Access

\begin{abstract}
Affected by many involved factors, different dimensions, data with large difference, incomplete information and so on, the most optimal selection of regional outburst prevention measures for outburst mine has become a complicated system project. The traditional way of outburst prevention measure selection belongs to qualitative method, which may cause high-cost of gas control, huge quantities of drilling work, long construction time and even secondary disaster. To solve the above-mentioned problems, in light of occurrence status of coal seam gas in No. 21 mining area of Jinzhushan Tuzhu Mine, through grey fixed weight clustering theory and a combination method of qualitative and quantitative analysis, the judging model with multi-objective classification for optimization of outburst prevention measures was established. The three weight coefficients of outburst prevention technology scheme are sorted, in order to determine the advantages and disadvantages of each outburst prevention technology scheme under the comprehensive evaluation of multi-target. Finally, the problem of quantitative selection for regional outburst prevention technology scheme is solved under the situation of multi-factor mode and incomplete information, which provides reasonable and effective technical measures for prevention of coal and gas outburst disaster.
\end{abstract}

\section{Keywords}

Coal-Gas Outburst, Grey Theory, Fixed Weight Clustering Analysis, Regional Outburst Prevention

"Corresponding author.

How to cite this paper: Luo, W.K., Shi, S.L., Lu, Y., Zou, S.H., Chen, Z.A. and Chen, L.L. (2016) Optimization Study of Outburst Prevention Measures for Tuzhu Coal Mine Based on Fixed Weight Clustering Analysis. Journal of Geoscience and Environment Protection, 4, 153-161. http://dx.doi.org/10.4236/gep.2016.41016 


\section{Measures}

\section{Introduction}

China is not only the country with the highest coal production from underground mining in the world, but also the main coal production country with the highest percentage mines with high gas and coal-gas outburst [1]-[3]. With the sustained growth of energy demand, depth of coal mining, coal output, intensive production, mining intensity and gas outburst disaster, it has increased along with the continuous development of underground mining [4] [5]. As a result of the increasing demand for energy especially coal, most mines in China have entered into deep mining with a speed of $20-50 \mathrm{~m} / \mathrm{a}$ [6] [7]. With the increase of mining depth, gas pressure and gas content, coal and gas outburst disasters are on the acceleration. Meanwhile, China has become the country with the most serious disasters of coal-gas outburst in the world. Through decades of theoretical research and engineering practice, the "four-in-one" comprehensive outburst prevention measure has been formed, which greatly enhanced the security of outburst coal seam mining [8] [9]. Regional outburst prevention measures include predrainage coal seam sector gas by surface drilling, pre-drainage coal seam sector gas by layer-through boring in floor roadway, pre-drainage coal seam sector gas by drilling along seam, pre-drainage coal roadway strips gas by layer-through boring, pre-drainage region gas when rock cross-cut coal uncovering by layer-through boring, pre-drainage gas in mining region by layer-through boring, pre-drainage gas in mining region by drilling along seam and so on [10]-[15]. On this basis, for the coal seam group mining, a variety of gas pre-drainage measures have evolved such as progressive bands with layer-through boring in floor roadway combined with pre-drainage area gas or strips gas by drilling along seam. During the traditional selection of regional outburst prevention measures, chief engineer of mining company chooses one of the feasible solutions and then approves to implement it. Due to the limitation of personal preference and knowledge level of chief engineers, the final implementation plan is not necessarily the best one. It has been found that there are still mine outbursts after the implementation of outburst prevention measures and there are also other disasters during the implementation process. Therefore, according to the fixed weight method of grey theory, for gas occurrence condition of specific areas, optimizing the preliminary feasible scheme with the multi-objective of the pre-drainage drilling quantities, drilling time, capital investment of gas control, the comprehensive cost of gas treatment and the control ability of secondary disasters will be important for outburst prevention and disaster reduction.

\section{Project Overview and Preliminary Plan}

\subsection{Overview of No. 21 Mining Area of Tuzhu Mine}

According to geological data, the No. 21 mining area is located in the middle of the southeastern wing of Qiaotouhe syncline in Jinzhushan Tuzhu Mine. The mining area, from 26th exploration line in the west to 200 meters east to 29th exploration line in the east, with the strike length of 1350 meters, dip length of 800 meters, covers a total area of 1080 square meters. The upper level of mining is -50 meters and the lower level is -250 meters. The mining area contains seven coal seams named the 1st, 2nd, 3rd, 4th, 5th, 6th and 7th coal seam, respectively. The 5th coal seam is the main mining coal seam, 2nd, 3rd and 4th coal seams could be exploited partly, while 1st, 6th and 7th couldn't be exploited.

\subsection{Preliminary Plan for Regional Outburst Prevention Measures of No. 21 Minging Area}

1) Plan I: Pre-drainage gas in 5 th coal seam by lots of crossing holes in floor roadway

That includes laying out one or two rock roadways in depth of 20 - 25 meters in the 5th coal seam floor within the No. 21 mining area, then constructing a drilling site every 50 meters in the rock roadway and lastly drilling holes in grid-style from bottom to top, as shown in Figure 1.

2) Plan II: Pre-drainage gas in the 5th coal seam by layer-through boring bands in floor roadway combined with drilling along seam

It includes laying out floor rock roadway in depth of 20 - 25 meters in the 5th coal seam floor within the No. 21 mining area, then constructing a drilling site in the rock roadway and lastly constructing grid-style crossing 


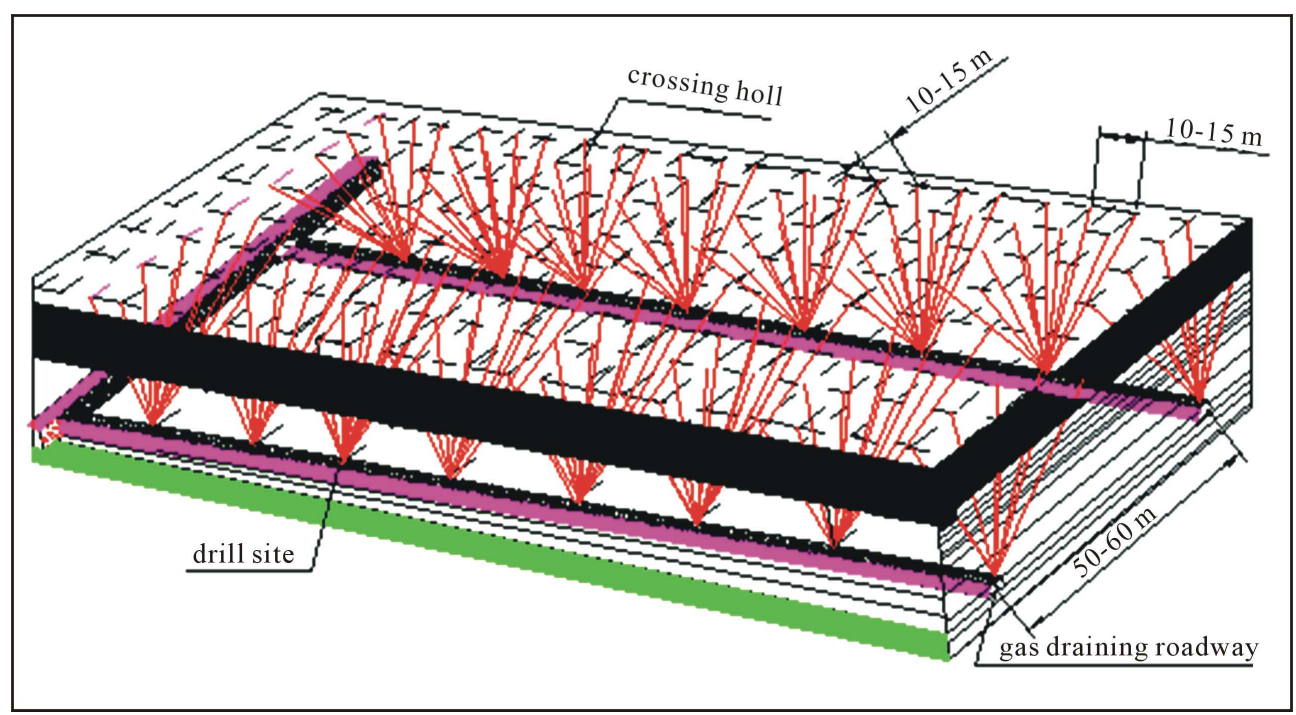

Figure 1. Sketch of crossing holes with grid-style layout in floor roadway.

hole to coal roadway, striving to eliminate the danger in coal roadway and its surrounding coal in a relatively short time by gas pre-drainage. Thus, it can be seen that gas pre-drainage by stripe drilling hole in floor rock roadway serve for tunneling of coal roadway, as shown in Figure 2.

3) Plan III: Progressive shielding gas pre-drainage in coal roadway

That includes constructing crossing hole in floor of 5th coal seam of No. 21 mining area to carry out striped gas pre-drainage for haulage roadway and return airway of 5th seam in the beginning; and then carrying out stripe regional gas pre-drainage for haulage roadway or return airway in 4th coal seam sector after the checksum meets the requirements. After the pressure meets the requirements of Outburst Prevention Regulations, constructing crossing hole in haulage roadway or return airway in 4th coal seam sector to carry out striped gas pre-drainage haulage roadway or return airway in 3th coal seam sector. After the pressure meets the requirements of Outburst Prevention Regulations, constructing crossing hole by the same method to carry out striped gas pre-drainage No. 2 coal seam (see Figure 3).

\subsection{Calculation of Optimizing Parameters in Schemes}

According to the above-mentioned three outburst prevention schemes on the No.21 mining area of Tuzhu mine, the performance computing of the three schemes are carried out from drilling work, construction time, investment of outburst prevention, gas control cost and prevention of secondary disasters, in order to optimize the most real data. According to the geographic features, the drilling length toward trending direction is 1390 meters and the drilling length toward the inclination is 840 meters (see Table 1).

\section{Classification Models of Optimized Objects}

\subsection{Mathematical Description}

The relative merits of regional outburst prevention solutions can be set as first class (best), second class (better) and third class (bad). Those three classes should be regarded as 3 standard modes, and outburst prevention solutions can be regarded as recognized objects, and their relative ownership can be finally determined by analyzing relative classification corresponding to 3 standard modes. As relative merits of regional outburst prevention solutions affected by several factors, it is a multi-factor recognition problem. Combined with the basic principles and basis of outburst prevention solutions, the property of judgments target for outburst prevention solutions will be grouped into 5 kinds of impact indicators including the total gas drilling work, construction time, investment of outburst prevention, gas control cost and prevention of secondary disasters. The standard modes are viewed as grey $K_{n}(n=1,2,3) . \quad X_{i j}(i=1,2,5 ; j=1,2, \cdots, 5)$ is set as the sample value of target $i$ with regard to in$\operatorname{dex} j . F_{j}^{k}(\cdot)(j=1,2, \cdots, 5 ; k=1,2,3)$ is set as Whitening weight function of decision-making index to $k$ subclass. 


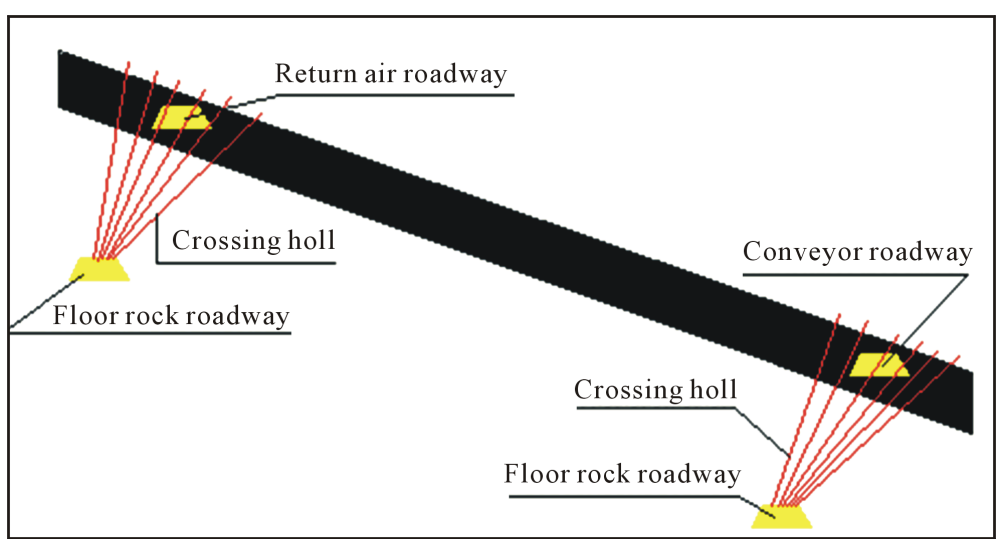

Figure 2. Drilling layout for intensive crossing hole and striped pre-drainage in floor rock roadway.

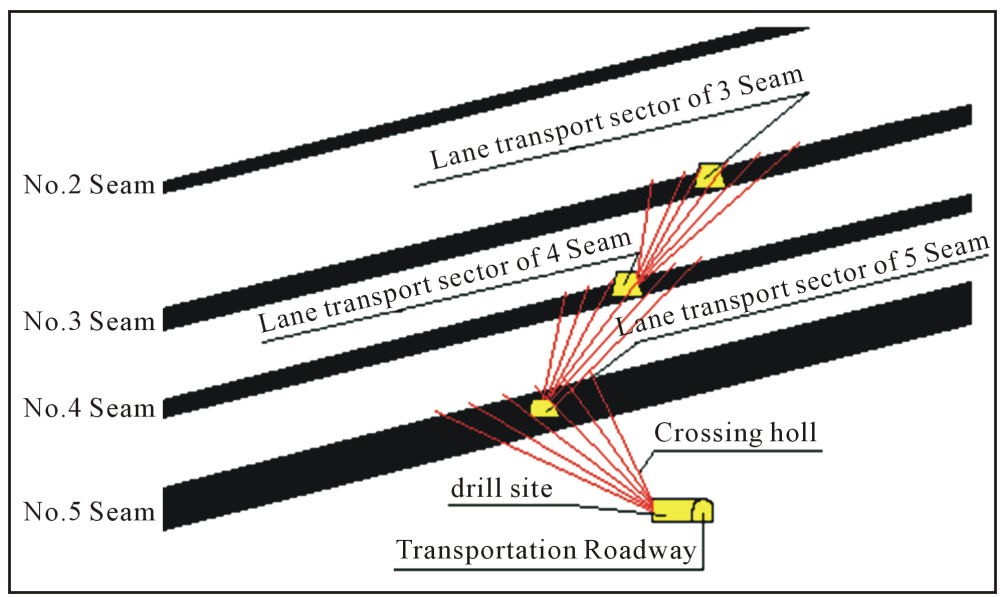

Figure 3. Drilling layout for progressive shield-style gas pre-drainage.

Table 1. Economic efficiency comparison of preliminary scheme of comprehensive outburst prevention in No. 21 mining area of Jinzhushan Tuzhu mine.

\begin{tabular}{cccccc}
\hline $\begin{array}{c}\text { Outburst prevention } \\
\text { schemes }\end{array}$ & $\begin{array}{c}\text { Drilling work } \\
\left(10^{5} \mathrm{~m}\right)\end{array}$ & $\begin{array}{c}\text { Construction time } \\
\left(10^{3}\right)\end{array}$ & $\begin{array}{c}\text { Investment } \\
\left(10^{6} \text { yuan }\right)\end{array}$ & $\begin{array}{c}\text { Gas control cost } \\
(\text { yuan/t) }\end{array}$ & $\begin{array}{c}\text { Prevention of } \\
\text { secondary disasters }\end{array}$ \\
\hline Scheme I & 14.95 & 24.92 & 52.33 & 63.39 & Average (75) \\
Scheme II & 13.54 & 13.54 & 20.31 & 53.29 & Better (80) \\
Scheme III & 15.15 & 15.16 & 22.74 & 82.56 & Good (95) \\
\hline
\end{tabular}

Here, function $\eta_{j}^{k}(j=1,2,3,4,5 ; k=1,2,3)$ of index $j$ to $k$ subclass is nothing with $k$. Namely, there is always $\eta_{j}^{k_{1}}=\eta_{j}^{k_{2}}$ to any $k_{1}, k_{2} \in\{1,2,3\}$, then the superscript could be omitted. It can be noted as $\eta_{j}(j=1,2,3,4,5)$ and be defined as $\sigma_{i}^{k}=\sum_{j=1}^{5} f_{j}^{k}\left(x_{i j}\right) \eta_{j}$, which is the grey fixed weight clustering coefficient of outburst prevention with regard to $i$ to $k$ grey class. If $\sigma_{i}^{k^{*}}=\max _{1 \leq k \leq 3}\left\{\sigma_{i}^{k}\right\}$, the target $i$ can be judged to belong to grey class $k^{*}$.

\subsection{The Division of Grey Classes}

The grey classes of the outburst prevention solutions for the No. 21 mining area can be divided into three classes, namely, best, better and bad. According to observations of each index, the standard gray classes of three levels 
can also be determined as shown in Table 2.

\subsection{Determination of Whitening Weight Function}

The first four of 5 indexes belong to cost variables, and the last index belongs to effective variables. To make calculation simple and the problem clear, the indexes and grey classes should be numbered. The whitening weight function with regard to $j$ index to $k$ subclass $F_{j}^{k}(\cdot)(j=1,2, \cdots, 5 ; k=1,2,3)$ can be expressed as follows (see Figure 4 and Table 3):

Table 2. Division of grey classes for preliminary regional outburst prevention solutions of No. 21 mining area in Jinzhushan Tuzhu mine.

\begin{tabular}{cccccc}
\hline Grey class & $\begin{array}{c}\text { Drilling work } \\
\left(10^{5} \mathrm{~m}\right)\end{array}$ & $\begin{array}{c}\text { Construction time } \\
\left(10^{3}\right)\end{array}$ & $\begin{array}{c}\text { investment } \\
\left(\text { RMB } 10^{6}\right)\end{array}$ & $\begin{array}{c}\text { Gas control cost } \\
(\text { Yuan/t) }\end{array}$ & $\begin{array}{c}\text { Prevention of secondary } \\
\text { disasters (\%) }\end{array}$ \\
\hline Best (I) & 7.5 & 8.9 & 15.9 & 33.2 & 126 \\
Better (II) & 15 & 17.8 & 31.8 & 66.4 & 84 \\
Bad (III) & 22.5 & 26.7 & 47.7 & 99.6 & 42 \\
\hline
\end{tabular}

Table 3. Whitening weight function $f_{j}^{k}(\cdot)$ list with regard to $j$ index to $k$ subclass.

\begin{tabular}{cccc}
\hline Evaluation index & $f_{j}^{1}(\cdot)$ & $f_{j}^{2}(\cdot)$ & $f_{j}^{3}(\cdot)$ \\
\hline Drilling work $\left(10^{5} \mathrm{~m}\right)$ & $f_{1}^{1}(-,-, 7.5,15)$ & $f_{1}^{2}(7.5,15,-, 22.5)$ & $f_{1}^{3}(15,22.5,-,-)$ \\
Construction time $\left(10^{3}\right.$ days) & $f_{2}^{1}(-,-, 8.9,17.8)$ & $f_{2}^{2}(8.9,17.8,-, 26.7)$ & $f_{2}^{3}(17.8,26.7,-,-)$ \\
Total investment (RMB $\left.10^{6}\right)$ & $f_{3}^{1}(-,-, 15.9,31.8)$ & $f_{3}^{2}(15.9,31.8,-, 47.7)$ & $f_{3}^{3}(31.8,47.7,-,-)$ \\
Control cost (Yuan/t) & $f_{4}^{1}(-,-, 33.2,66.4)$ & $f_{4}^{2}(33.2,66.4,-, 99.6)$ & $f_{4}^{3}(66.4,99.6,-,-)$ \\
Prevention of secondary disaster (\%) & $f_{5}^{1}(84,126,-,-)$ & $f_{5}^{2}(42,84,-, 126)$ & $f_{5}^{3}(-,-, 42,84)$ \\
\hline
\end{tabular}

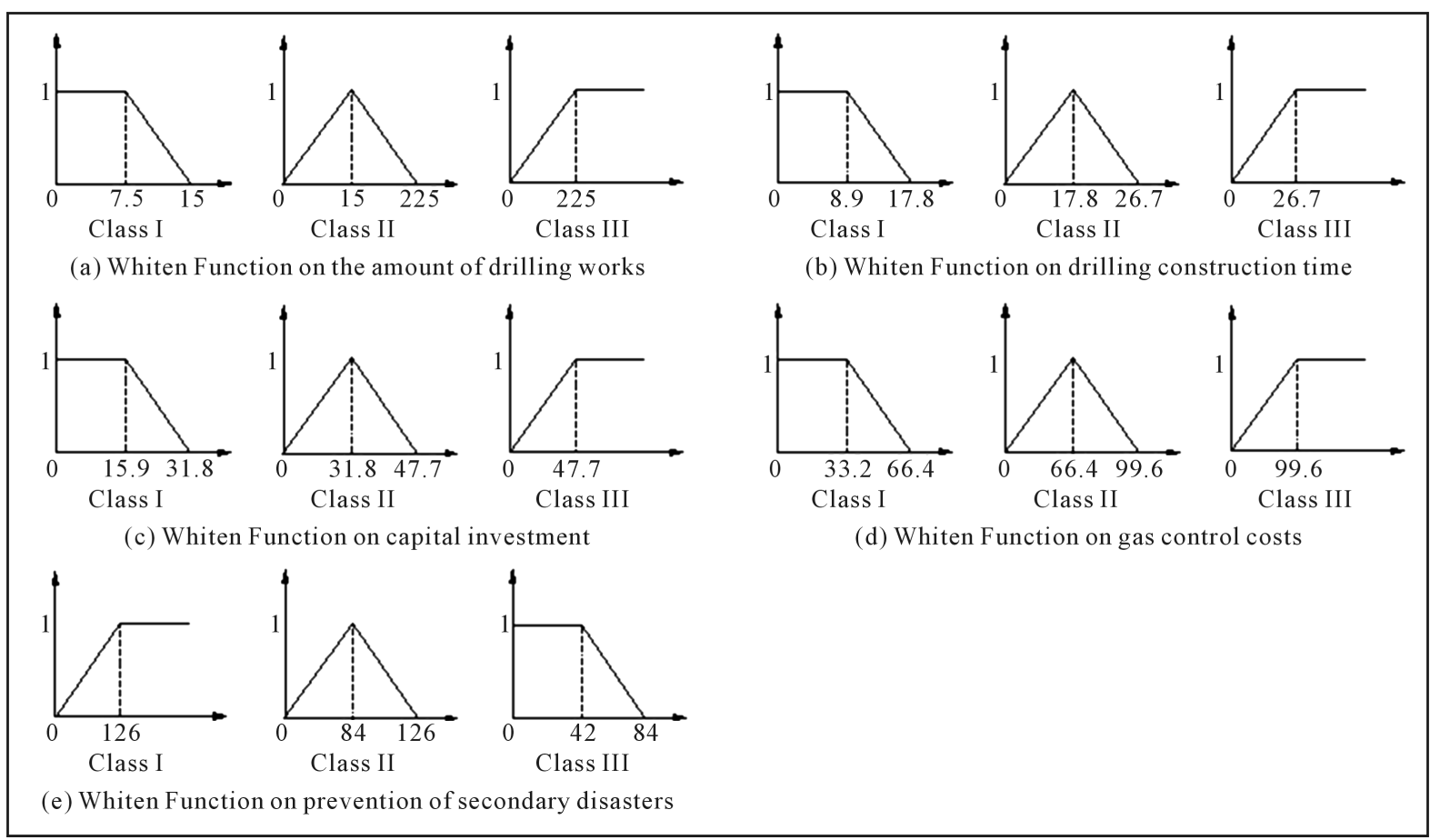

Figure 4. Whitening weight function with regard to $j$ index to $k$ subclass. 
1) Whitening weight function I

$$
f_{j}^{k}(x) \begin{cases}0 & x \prec x_{j}^{k}(1) \\ \frac{x-x_{j}^{k}(1)}{x_{j}^{k}(2)-x_{j}^{k}(1)} & x \in\left[x_{j}^{k}(1), x_{j}^{k}(2)\right] \\ 1 & x \geq x_{j}^{k}(2)\end{cases}
$$

2) Whitening weight function II

$$
f_{j}^{k}(x) \begin{cases}0 & x \notin\left[x_{j}^{k}(1), x_{j}^{k}(4)\right] \\ \frac{x-x_{j}^{k}(1)}{x_{j}^{k}(2)-x_{j}^{k}(1)} & x \in\left[x_{j}^{k}(1), x_{j}^{k}(2)\right] \\ \frac{x_{j}^{k}(4)-x}{x_{j}^{k}(4)-x_{j}^{k}(1)} & x \in\left[x_{j}^{k}(2), x_{j}^{k}(4)\right]\end{cases}
$$

3) Whitening weight function III

$$
f_{j}^{k}(x) \begin{cases}0 & x \notin\left[0, x_{j}^{k}(4)\right] \\ 1 & x \in\left[0, x_{j}^{k}(3)\right] \\ \frac{x_{j}^{k}(4)-x}{x_{j}^{k}(4)-x_{j}^{k}(3)} & x \in\left[x_{j}^{k}(3), x_{j}^{k}(4)\right]\end{cases}
$$

\section{Calculation of Fixed Weight Clustering Coefficient}

\subsection{Determination of Clustering Weights}

According to the available information of Tuzhu mine, weights of drilling quantities, construction time, investment, gas control cost and prevention of secondary disaster are identified by project team and technical personnel of mine as: $\eta_{1}=0.1512, \eta_{2}=0.1512, \eta_{3}=0.1441, \eta_{4}=0.4094, \eta_{5}=0.1441$.

\subsection{Calculation of Clustering Coefficient}

It can be calculated from formula 1 : when $i=1$ and $k=1,2,3$,

$$
\begin{aligned}
\sigma_{1}^{1}= & \sum_{j=1}^{5} f_{j}^{1}\left(x_{i j}\right) \cdot \eta_{j}=f_{1}^{1}(14.95) \times 0.1512+f_{2}^{1}(24.95) \times 0.1512 \\
& +f_{3}^{1}(52.33) \times 0.1441+f_{4}^{1}(63.39) \times 0.4094+f_{5}^{1}(75) \times 0.1441 \\
= & \frac{14.95-7.5}{7.5} \times 0.1512+0+0+\frac{63.39-33.2}{33.2} \times 0.0 .4094 \\
= & 0.5224
\end{aligned}
$$

when $i=1$ and $k=2$,

$$
\begin{aligned}
\sigma_{1}^{2}= & \sum_{j=1}^{5} f_{j}^{2}\left(x_{i j}\right) \cdot \eta_{j}=f_{1}^{2}(14.95) \times 0.1512+f_{2}^{2}(24.95) \times 0.1512 \\
& +f_{3}^{2}(52.33) \times 0.1441+f_{4}^{2}(63.39) \times 0.4094+f_{5}^{2}(75) \times 0.1441 \\
= & \frac{14.95-7.5}{7.5} \times 0.1512+\frac{24.95-17.8}{17.8} \times 0.1512+0+1 \times 0.4094+\frac{75-42}{42} \times 0.1441 \\
= & 0.7333 .
\end{aligned}
$$


when $i=1$ and $k=2$,

$$
\begin{aligned}
\sigma_{1}^{3}= & \sum_{j=1}^{5} f_{j}^{3}\left(x_{i j}\right) \cdot \eta_{j}=f_{1}^{3}(14.95) \times 0.1512+f_{2}^{3}(24.95) \times 0.1512 \\
& +f_{3}^{3}(52.33) \times 0.1441+f_{4}^{3}(63.39) \times 0.4094+f_{5}^{3}(75) \times 0.1441 \\
= & \frac{14.95-7.5}{7.5} \times 0.1512+1 \times 0.1512+1 \times 0.1441 \\
& +\frac{63.39-33.2}{33.2} \times 0.4094+\frac{75-42}{42} \times 0.1441 \\
= & 0.9309 .
\end{aligned}
$$

So,

$$
\sigma_{1}=\left(\sigma_{1}^{1}, \sigma_{1}^{2}, \sigma_{1}^{3}\right)=(0.5224,0.7333,0.9039)
$$

It also can be calculated that,

$$
\begin{gathered}
\sigma_{2}=\left(\sigma_{2}^{1}, \sigma_{2}^{2}, \sigma_{2}^{3}\right)=(1.000,0.6187,0.6324), \\
\sigma_{3}=\left(\sigma_{3}^{1}, \sigma_{3}^{2}, \sigma_{3}^{3}\right)=(0.7977,0.6330,0.8532) .
\end{gathered}
$$

\subsection{Clustering Analysis}

Every preliminary outburst prevention solutions corresponding to $k$ class has a relevant clustering coefficient. In clustering coefficients, the level corresponding to the coefficient with the largest value is the one that clustering samples belong to. According to above results, the grey clustering coefficient matrix can be expressed as follows:

$$
\sum=\left(\sigma_{i}^{k}\right)=\left[\begin{array}{lll}
\sigma_{1}^{1} & \sigma_{1}^{2} & \sigma_{1}^{3} \\
\sigma_{2}^{1} & \sigma_{2}^{2} & \sigma_{2}^{3} \\
\sigma_{3}^{1} & \sigma_{3}^{2} & \sigma_{3}^{3}
\end{array}\right]\left[\begin{array}{ccc}
0.5224 & 0.7333 & 0.9039 \\
1.000 & 0.6187 & 0.6324 \\
0.7977 & 0.6330 & 0.8532
\end{array}\right]
$$

It can be inferred from the above-mentioned grey fixed weight clustering matrix that

$\max _{1 \leq k \leq 3}\left\{\sigma_{1}^{k}\right\}=\sigma_{1}^{3}=0.9039, \max _{1 \leq k \leq 3}\left\{\sigma_{2}^{k}\right\}=\sigma_{2}^{1}=1.000, \max _{1 \leq k \leq 3}\left\{\sigma_{3}^{k}\right\}=\sigma_{3}^{3}=0.8532$. Judging from the comprehensive evaluation results of drilling work, construction time, investment, gas control cost and prevention of secondary disaster in the preliminary outburst preventions of No. 21 mining area, the second solution is the best, the first is better, while the third one is relatively poor.

Thus, the second regional outburst prevention solution would be implemented in the Tuzhu Mine, namely, the outburst prevention technology of floor layer-through strip combined with drilling along coal seam mode would be carried out in the No. 21 mining area.

\section{Implementation Effect}

To investigate the implementation effect of regional outburst prevention solution in No. 21 mining area of Tuzhu Mine, the $1^{\#}$ and $2^{\#}$ boreholes were drilled at $4^{\#}$ and $6^{\#}$ drilling site in floor roadway to observe the gas pressure relief effect in No. 5 coal seam. The installation of pressure monitoring hole is as shown in Figure 5 in order to detect regional gas pressure relief after the implementation of the scheme II.

The inspection time lasted from March 1 to March 31, 2012. Data was collected once every four days from each pressure gauge. As shown in Figure 6, the gas pressures of $1^{\#}$ and $2^{\#}$ boreholes in $6^{\#}$ drilling site were 1.2 MPa in the first observation. After the gas drainage last 18 days, the coal seam gas pressure dropped below 0.74 MPa specified in Regulations on Prevention and Control of Coal and Gas Outburst, while the gas pressures of $1^{\#}$ and $2^{\#}$ boreholes in the $4^{\#}$ drilling site were 1.5 MPa and 1.4 MPa respectively in the first observation, and the gas pressures of $1^{\#}$ and $2^{\#}$ boreholes dropped below the requirement of Regulations on Prevention and Control of Coal and Gas Outburst after 25 days and 28 days respectively. 


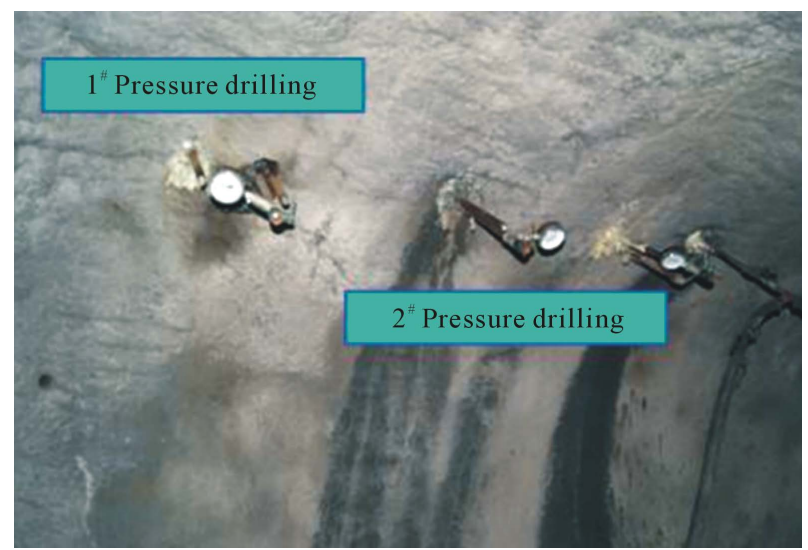

Figure 5. Drilling hole installation for relief effect test in the No. 21 mining area.

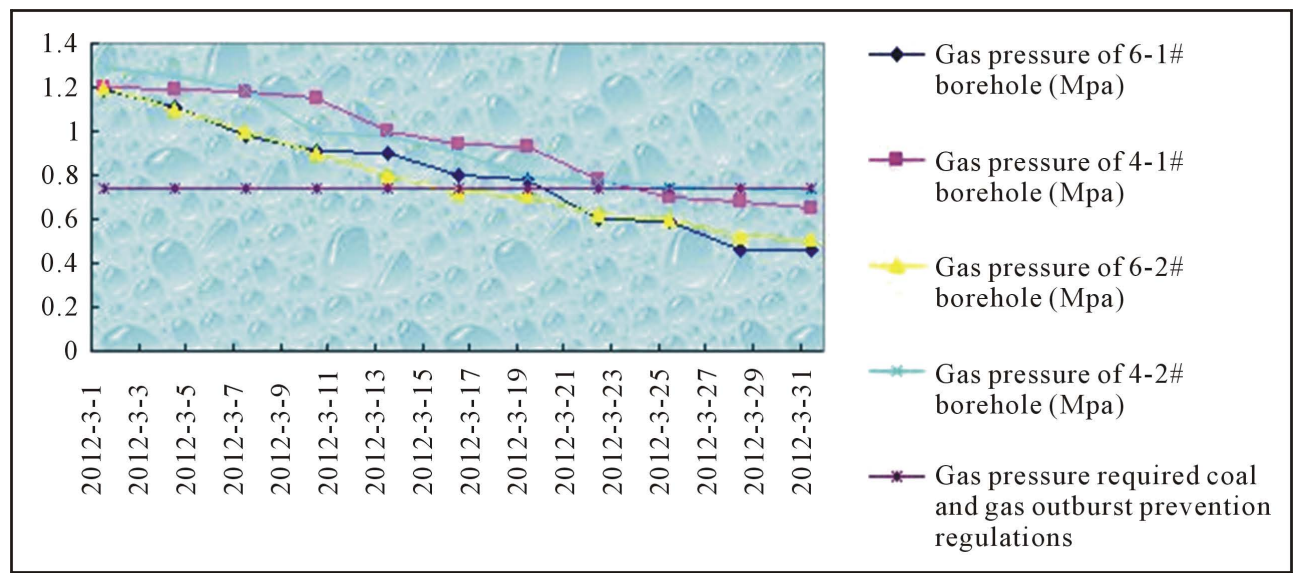

Figure 6. Variation curve of boreholes gas pressure in $6^{\#}$ and $4^{\#}$ drilling site.

\section{Conclusions}

There are many kinds of regional outburst prevention measures. How to choose the correct regional outburst prevention measures is important for the normal replacement of working face, the decreasing the drilling quantities of outburst prevention and saving the cost of outburst prevention. In light of occurrence status of coal seam gas in No. 21 mining area of Jinzhushan Tuzhu mine, through grey fixes weight clustering theory and a combination method of qualitative and quantitative analysis, the judging model with multi-objective classification for optimization of outburst prevention measures is established.

In particular, the three feasible preliminary regional outburst prevention measures are stated as follows. The first is pre-drainage gas in 5th coal seam by lots of crossing holes in floor roadway; the second is pre-drainage gas in the 5th coal seam by layer-through boring bands in floor roadway combined with drilling along seam and the third is progressive shielding gas pre-drainage in coal roadway. Optimized objects are drilling work, construction time, investment of outburst prevention, gas control cost and prevention of secondary disasters.

The results show that the second measure is the best, the first is better, while the third one is relatively poor. Based on the application effect, the unloading speed of second measure is quick, the unloading time is short. It provides a powerful guarantee for the normal replacement of coal mining working face.

\section{Acknowledgements}

This work was supported by the Nation Science Foundation Project (51274100, 51274098), Hunan Province Science and Technology Plan General Projects (2012FJ4268) and Hunan Provincial Education Department General Project (13C307). 


\section{References}

[1] Pan, Y. and Li, A. (2013) Rapid Iterative Incremental Model of the Intermittent Chaos of Deep Hole Developing in Coal-Gas Outburst. International Journal of Mining Science \& Technology, 23, 287-292. http://dx.doi.org/10.1016/j.ijmst.2013.04.005

[2] Otuonye, F. and Sheng, J. (1994) A Numerical Simulation of Gas Flow during Coal/Gas Outbursts. Geotechnical \& Geological Engineering, 12, 15-34. http://dx.doi.org/10.1007/BF00425934

[3] Cai, F. (2012) Numerical Simulation Research on Coal-Gas Outburst in the Process of Development. Applied Mechanics \& Materials, 204-208, 3377-3383. http://dx.doi.org/10.4028/www.scientific.net/AMM.204-208.3377

[4] Yang, S., Tang, J., Wen, G., Kang, J. and Liu, C. (2012) Coal and Gas Outburst Disaster Early Warning and Emergency Response Decision Support Technology. Journal of Chongqing University, 35, 121-125.

[5] Liu, J., Wang, E., Song, D., Wang, S. and Niu, Y. (2014) Effect of Rock Strength on Failure Mode and Mechanical Behavior of Composite Samples. Arabian Journal of Geosciences, 8, 1-13.

[6] Chen, X., Li, W. and Yan, X. (2012) Analysis on Rock Burst Danger When Fully-Mechanized Caving Coal Face Passed Fault with Deep Mining. Safety Science, 50, 645-648. http://dx.doi.org/10.1016/j.ssci.2011.08.063

[7] Konicek, P., Soucek, K., Stas, L. and Singh, R. (2013) Long-Hole Destress Blasting for Rock-Burst Control during Deep Underground Coal Mining. International Journal of Rock Mechanics \& Mining Sciences, 61, 141-153. http://dx.doi.org/10.1016/j.ijrmms.2013.02.001

[8] Hao, F., Liu, M. and Sun, L. (2011) Study on Comprehensive Technology of Coal and Gas Outburst Prevention in Mining Panels. Procedia Engineering, 26, 699-703. http://dx.doi.org/10.1016/j.proeng.2011.11.2225

[9] Shen, R., Wang, E., Xu, W.Q., Feng, X. and Hu, S.B. (2011) Outburst Prevention and Control Technology of Thin Coal Zone in Island Coal Face with Potential Outburst. Procedia Engineering, 26, 56-62.

[10] Chen, L.W. and Chen, J.C. (2012) Technology of Strip Gas Pre-Drainage with Boreholes along Coal Seam from Front Traverse. Advanced Materials Research, 524-527, 752-757. http://dx.doi.org/10.4028/www.scientific.net/AMR.524-527.752

[11] Jiang, J., Cheng, Y., Zhang, P., Jin, K., Cui, J. and Du, H. (2015) Cbm Drainage Engineering Challenges and the Technology of Mining Protective Coal Seam in the Dalong Mine, Tiefa Basin, China. Journal of Natural Gas Science \& Engineering, 24, 412-424. http://dx.doi.org/10.1016/j.jngse.2015.04.001

[12] Zou, Q.L., Lin, B.Q., Liu, T., Zhou, Y., Zhang, Z. and Yan, F.Z. (2014) Variation of Methane Adsorption Property of Coal after the Treatment of Hydraulic Slotting and Methane Pre-Drainage: A Case Study. Journal of Natural Gas Science \& Engineering, 20, 396-406. http://dx.doi.org/10.1016/j.jngse.2014.07.024

[13] Lu, Y. and Qin, B. (2015) Identification and Control of Spontaneous Combustion of Coal Pillars: A Case Study in the Qianyingzi Mine, China. Natural Hazards, 75, 2683-2697. http://dx.doi.org/10.1007/s11069-014-1455-2

[14] Lu, Y. and Qin, B. (2015) Mechanical Properties of Inorganic Solidified Foam for Mining Rock Fracture Filling. Materials Express, 5, 291-299. http://dx.doi.org/10.1166/mex.2015.1244

[15] Lu, Y., Shen, H., Qin, B., Zhang, L., Ma, H. and Mao, T. (2015) Gas Drainage Radius and Borehole Distance along Seam. Journal of Mining \& Safety Engineering, 32, 156-162. 